\title{
Tonic Investigation Concept of Cervico-vestibular Muscle Afferents
}

\author{
Linda Josephine Dorn ${ }^{1}$ Annabelle Lappat ${ }^{2}$ Winfried Neuhuber ${ }^{3}$ Hans Scherer ${ }^{1}$ Heidi Olze ${ }^{1}$ \\ Matthias Hölz| ${ }^{4}$ \\ ${ }^{1}$ Department of Otorhinolaryngology, Charité Universitätsmedizin, \\ Berlin, Germany \\ ${ }^{2}$ Department of Otorhinolaryngology, Sankt Gertrauden Hospital, \\ Berlin, Germany \\ 3 Institute of Anatomy, Universität Erlangen-Nürnberg, \\ Erlangen-Nürnberg, Germany \\ ${ }^{4}$ Department of Otorhinolaryngology, Universitätsklinik Magdeburg, \\ Magdeburg, Germany \\ Int Arch Otorhinolaryngol 2017;21:46-57. \\ Address for correspondence Linda Josephine Dorn, Department of \\ Otorhinolaryngology, Charité Universitätsmedizin, Charitéplatz 1, \\ Berlin 10117, Germany (e-mail: linda-josephine.dorn@charite.de).
}

\begin{abstract}
Keywords

- vertical nystagmus

- cervical nystagmus

- cervical vertigo

- TENS

- neck torsion test

- trunk excursion chair
\end{abstract}

Introduction Interdisciplinary research has contributed greatly to an improved understanding of the vestibular system. To date, however, very little research has focused on the vestibular system's somatosensory afferents. To ensure the diagnostic quality of vestibular somatosensory afferent data, especially the extra cranial afferents, stimulation of the vestibular balance system has to be precluded.

Objective Sophisticated movements require intra- and extra cranial vestibular receptors. The study's objective is to evaluate an investigation concept for cervico-vestibular afferents with respect to clinical feasibility.

Methods A dedicated chair was constructed, permitting three-dimensional trunk excursions, during which the volunteer's head remains fixed. Whether or not a cervicotonic provocation nystagmus (c-PN) can be induced with static trunk excursion is to be evaluated and if this can be influenced by cervical monophasic transcutaneous electrical nerve stimulation (c-TENS) with a randomized test group. 3D-video-oculography (VOG) was used to record any change in cervico-ocular examination parameters. The occurring nystagmuses were evaluated visually due to the small caliber of nystagmus amplitudes in healthy volunteers.

Results The results demonstrate: no influence of placebo-controlled c-TENS on the spontaneous nystagmus; a significant increase of the vertical nystagmus on the 3Dtrunk-excursion chair in static trunk flexion with cervical provocation in all young healthy volunteers $(n=49)$; and a significant difference between vertical and horizontal nystagmuses during static trunk excursion after placebo-controlled c-TENS, except for the horizontal nystagmus during trunk torsion.

Conclusion We hope this cervicotonic investigation concept on the 3D trunk-excursion chair will contribute to new diagnostic and therapeutic perspectives on cervical pathologies in vestibular head-to-trunk alignment. received

November 23, 2015

accepted

February 24, 2016

published online

May 5, 2016
DOI http://dx.doi.org/

10.1055/s-0036-1583759.

ISSN 1809-9777.
Copyright (c) 2017 by Thieme-Revinter

Publicações Ltda, Rio de Janeiro, Brazil
License terms

() (1) $\odot \circledast$ 


\section{Introduction}

Coordination of the head and trunk within the constraints of gravity is an important aspect of human coordination. The perception of spatial orientation depends on the integration of visual, otolith, semicircular canal, and proprioceptive information (-Fig. 1). ${ }^{1}$ Recent research has contributed to an improved understanding of the three vestibular intracranial receptor systems (eyes, otolith, and the semicircular canals). ${ }^{2-4}$ Studies at zero gravity have shown that the vestibular sensory hierarchy permits dynamic changes that increase proprioceptive performance. ${ }^{5,6}$ Three-dimensional (3D) movements in space require vestibular coordination of intra- and extracranial receptor information, due to the varying positions of the head relative to the trunk. Two-thirds of the extracranial vestibular signals are generated by proprioceptors in the upper cervical spine (CS) (f). ${ }^{7,8}$ Neuroanatomical studies show both primary afferent proprioceptive projections ${ }^{7}$ from the cervical and nuchal musculature, as well as secondary afferent projections ${ }^{7}$ from the central cervical nucleus in $\mathrm{C}-4^{8}$ (the most important spinal relay nucleus for spinal afferents from the nuchal musculature ${ }^{9,10}$ ) to the vestibular nucleic complex. ${ }^{7}$ Electrophysiological experiments have demonstrated a convergence of cervical proprioceptors and labyrinthine afferents to the vestibular nucleic complex neurons. ${ }^{11}$
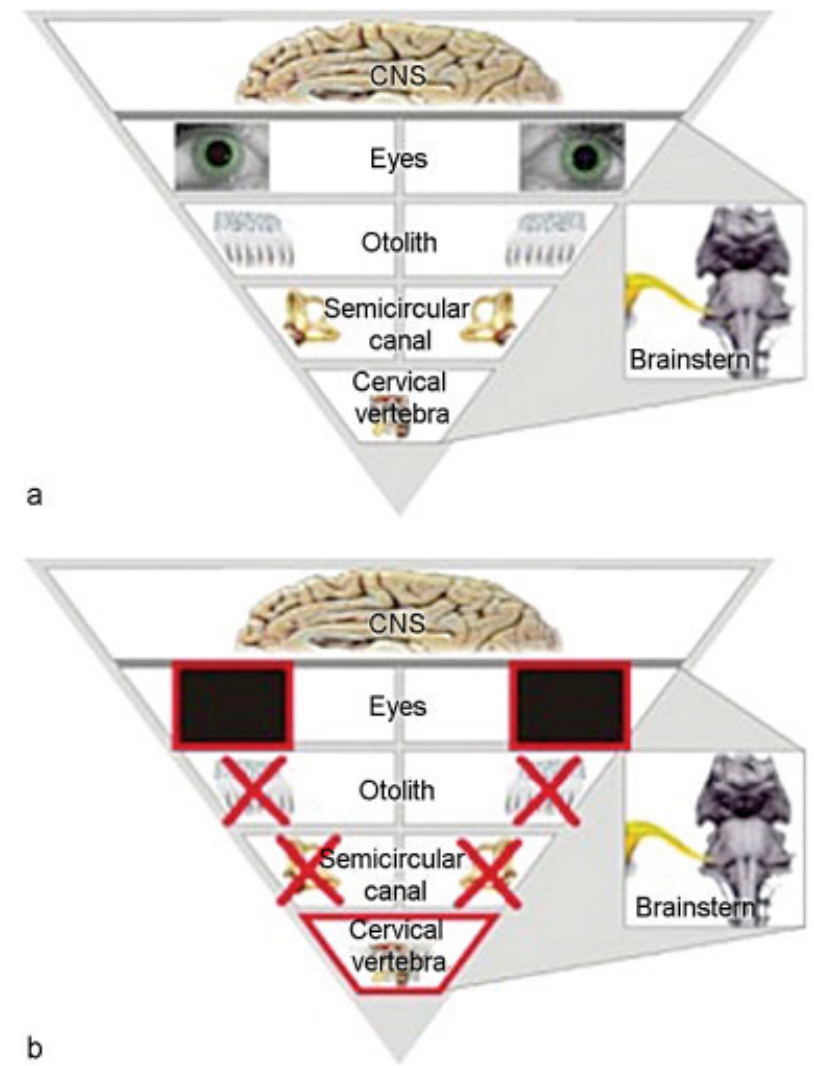

Fig.1 (a) The figure illustrates the receptor hierarchy in decreasing physiological dominance of the intracranial and extra cranial vestibular receptors, i.e. the optical, the otolith, the semi-circular, and the somatosensory system. (b) The figure illustrates the ideal conditions for an examination of the extra cranial vestibular receptors.
To identify the cervical origin of vertigo in a patient, some physicians use the so-called "head torsion test". Nystagmus that occurs during neck torsion (phasic examination) and nystagmus that occurs in a fixed head position (tonic examination) must be distinguished. Holtmann et al have previously reported on cervical-induced horizontal nystagmuses under phasic reflex conditions in a fully-automated trunk torsion chair. ${ }^{12}$ Due to the complexity of the study design, their approach was not followed here. In this study, we refer to the basic idea of Holtmann et al and introduce an improved study design based on tonic investigative principles: an exam that uses neuronal la fiber afferents on the one hand and precludes reflex conditions on the other hand.

With this innovation, common sources of data errors, such as vigilance, training, among others, can be prevented, and the examination itself is greatly simplified.

Preliminary studies have shown the diagnostic relevance of vertical nystagmus, particularly during tonic cervicalstrained head flexion. The up-beat nystagmus has been shown to differentiate cervical from vestibular pathology. ${ }^{13}$

In this study, we continually monitored cervical-tonicinduced horizontal and vertical nystagmuses using videooculography (VOG) and recorded these in three dimensions. The nystagmus will be referred to as "cervicotonic provocation nystagmus (c-PN)" in this manuscript. The authors attribute this nystagmus to the fact that physiological conditions for the vestibular system are achieved by vertical alignment of the eyes, otoliths, and semicircular canals (i.e. intra cranial receptors). One of the most essential tasks of head-trunk coordination is to ensure the ideal spatial orientation of the head in daily life ( - Fig. 2). Cervical receptor competence in the vestibular system is crucial for this task. ${ }^{14,15}$ However, the best way to assess and quantify the extracranial receptors using objective parameters remains to be determined. Thus, the aim of this study

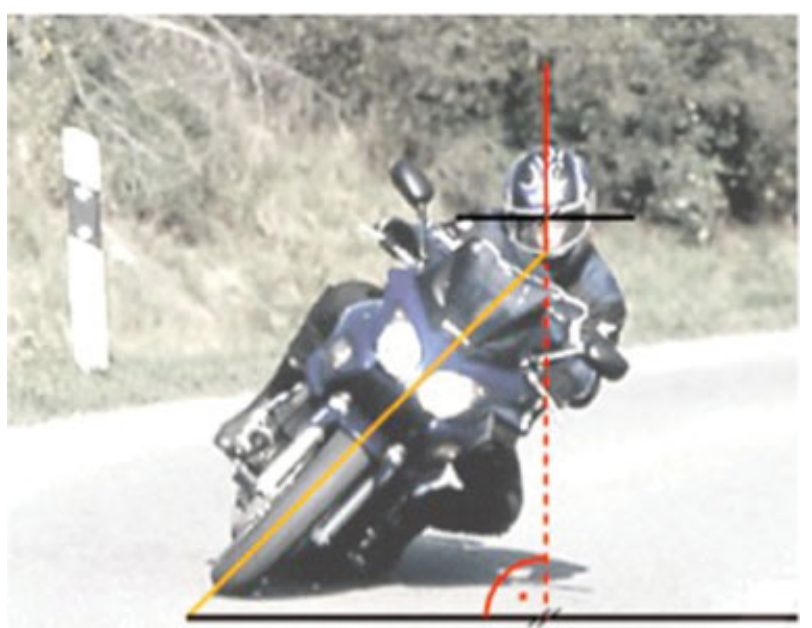

Fig. 2 Cervical proprioceptive action during a motorcycle drivers' curve passage. In high performance conditions of the ideal curve the motorcycle driver needs obviously a correctly positioned trunk angle, which is not detectable by the intracranial vestibular receptors. The extra cranial adjustment occurs in close interaction with intracranial receptor information. 
was to provide objective measurement parameters in a clinically feasible setting, with simple documentation of vestibular-somatic afferent information.

\section{Materials and Methods}

We investigated whether the cervical afferents alone would induce a documentable cervico-ocular nystagmus. We performed the measurements with the head in a static vertical positioning and various static trunk positions. We assessed a method of tonic cervico-ocular investigation with respect to clinical feasibility. Minimal preliminary research exists on this method. ${ }^{16}$ We used a self-developed 3D-trunk-excursion-chair (-Fig. 3 and Chapter 2.2.). The 3D-trunk-excursion-chair was constructed to permit three-dimensional trunk excursions (punctum mobile), during which the volunteer's head remained fixed (punctum fixum). Throughout the test, the video-oculography system functioned as visual barrier to prevent optical fixation. The chair was specifically designed to target the upper cervical spine during the various static trunk positions (- Fig. 1b).

Our objective was to evaluate whether a cervicotonic provocation nystagmus (c-PN) can be triggered in this setup, and whether this can be influenced by cervical transcutaneous electrical nerve stimulation (c-TENS).

\section{Cervical Transcutaneous Electrical Nerve Stimulation (c-TENS)}

Cervical transcutaneous electrical nerve stimulation (c-TENS) is a medical stimulation current therapy that uses mono (continuous current) or biphasic (alternating current) lowfrequency square pulses. c-TENS is a non-pharmaceutical and non-invasive treatment concept that is used predominantly in pain therapy. Like the delicate dynamic afferents, monophasic TENS reaches even large-caliber spinal muscle afferents. ${ }^{17}$

The study design was based on the hypothesis notion, that monophasic c-TENS at the upper cervical spinal levels (C1-C3) induces a decrease in the action potential frequency of proprioceptive conduction. ${ }^{17}$ A significant difference between the control and placebo group would therefore suggest the contribution of cervical afferents to head-to-trunk coordination.

Monitoring of motor components of c-TENS was not possible in the described set-up. However, the effects of c-TENS are manifested as hypoesthesia of corresponding sensory zones of the head. A difference between the control and test group would suggest that cervical afferents play a role in headtrunk-coordination.

\section{Three-Dimensional Trunk-Excursion Chair}

The examination chair (-Fig. 3) was designed and built using high-quality materials, taking into consideration the mechanical
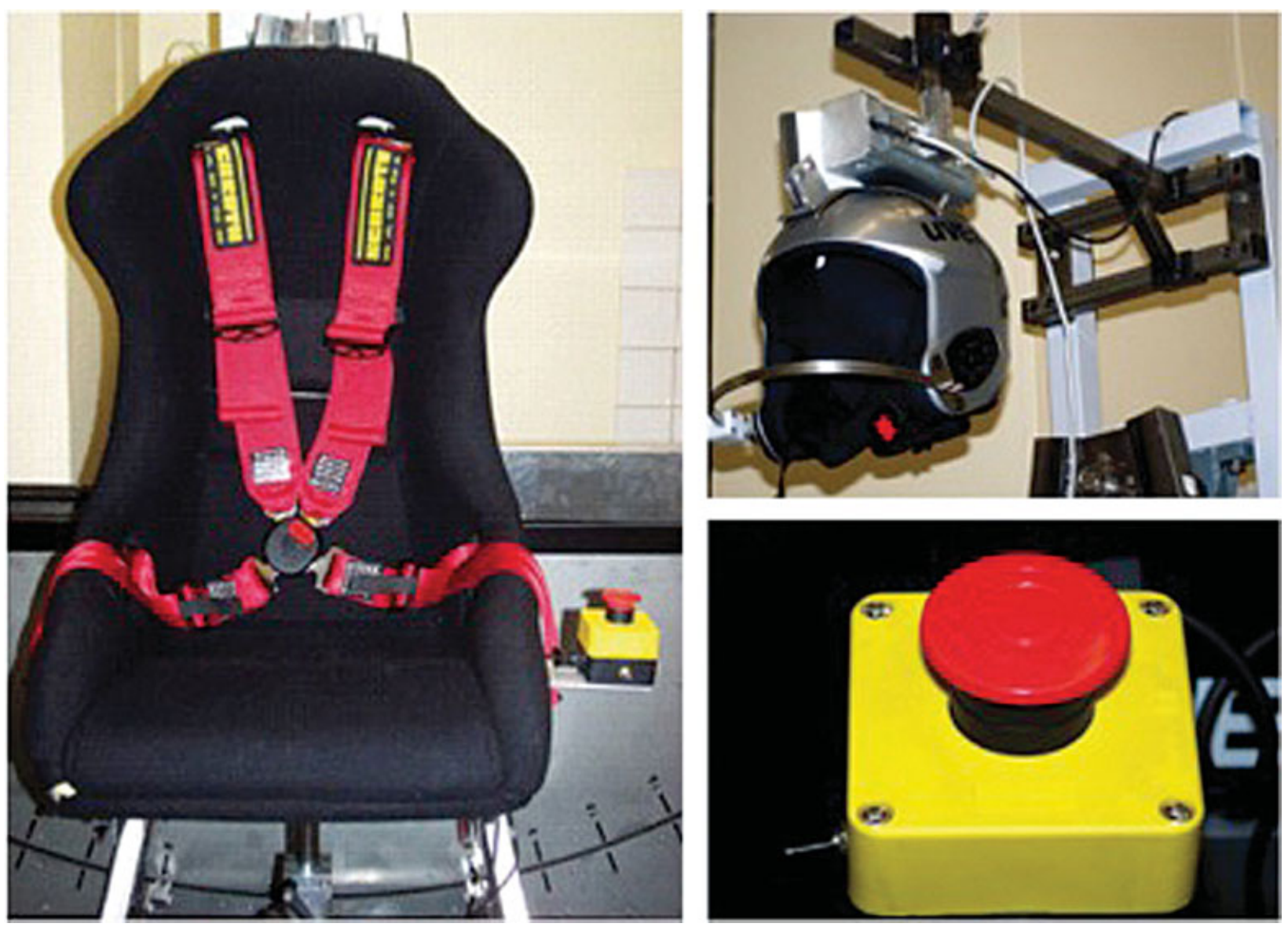

Fig. 3 Image of the 3D- trunk-excursion chair with a 4-point seat belt by Recaro (left). Enlarged Image of the so-called "emergency release button" and the magnetically fixated helmet (right). The release button enables the volunteer to terminate the experiment by releasing the magnet (right). 
Table 1 Nystagmus evaluation chart

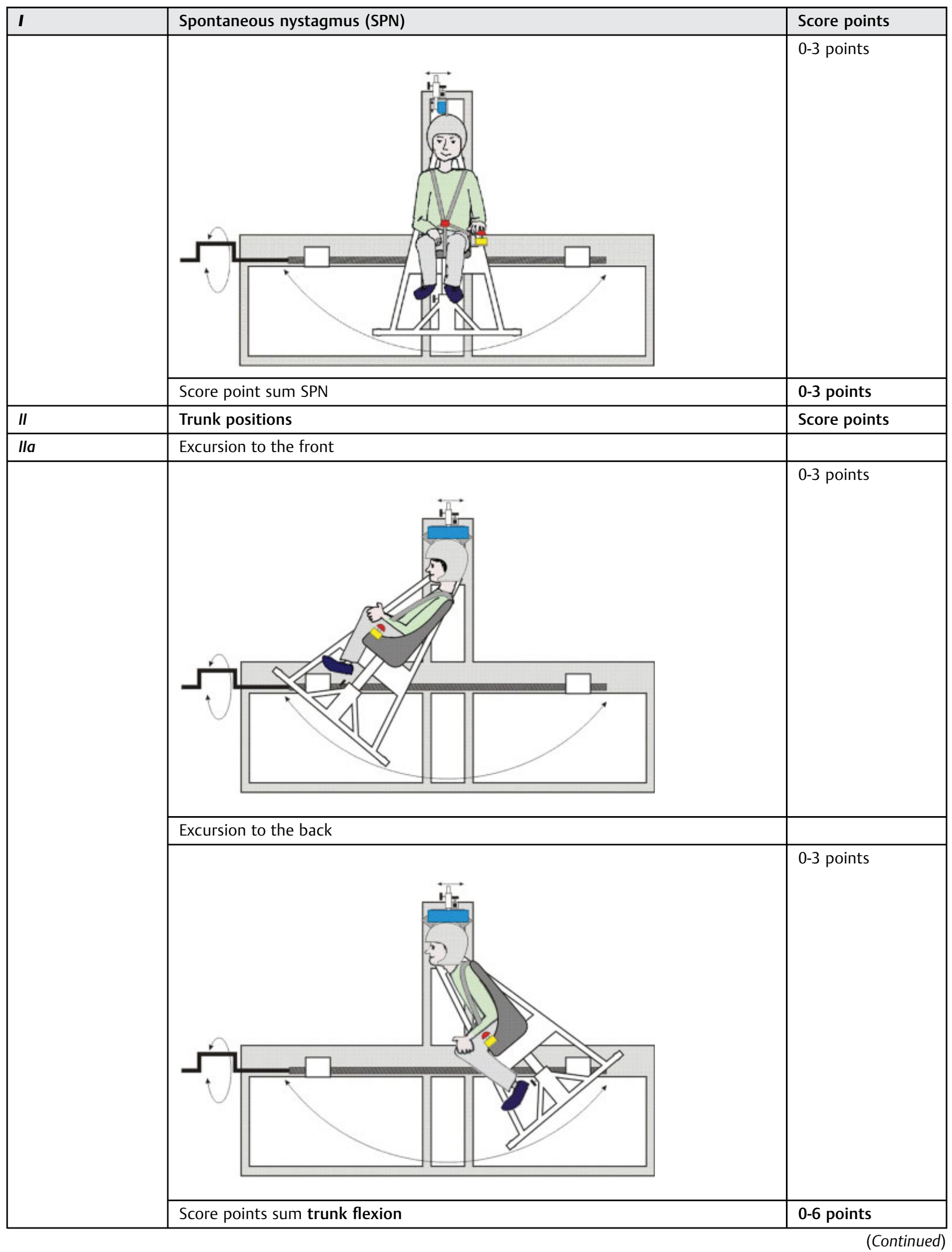


Table 1 (Continued)

\begin{tabular}{|c|c|c|}
\hline$I$ & Spontaneous nystagmus (SPN) & Score points \\
\hline \multirow[t]{5}{*}{$11 \mathrm{lb}$} & Side tilt to the right & Score points \\
\hline & & \multirow[t]{2}{*}{$0-3$ points } \\
\hline & Side tilt to the left & \\
\hline & & \multirow[t]{2}{*}{ 0-3 points } \\
\hline & Score points sum trunk tilt & \\
\hline \multirow[t]{4}{*}{ IIc } & Pivots around axis to the right & Score points \\
\hline & & \multirow[t]{2}{*}{$0-3$ points } \\
\hline & Pivots around axis to the left & \\
\hline & & 0-3 points \\
\hline
\end{tabular}




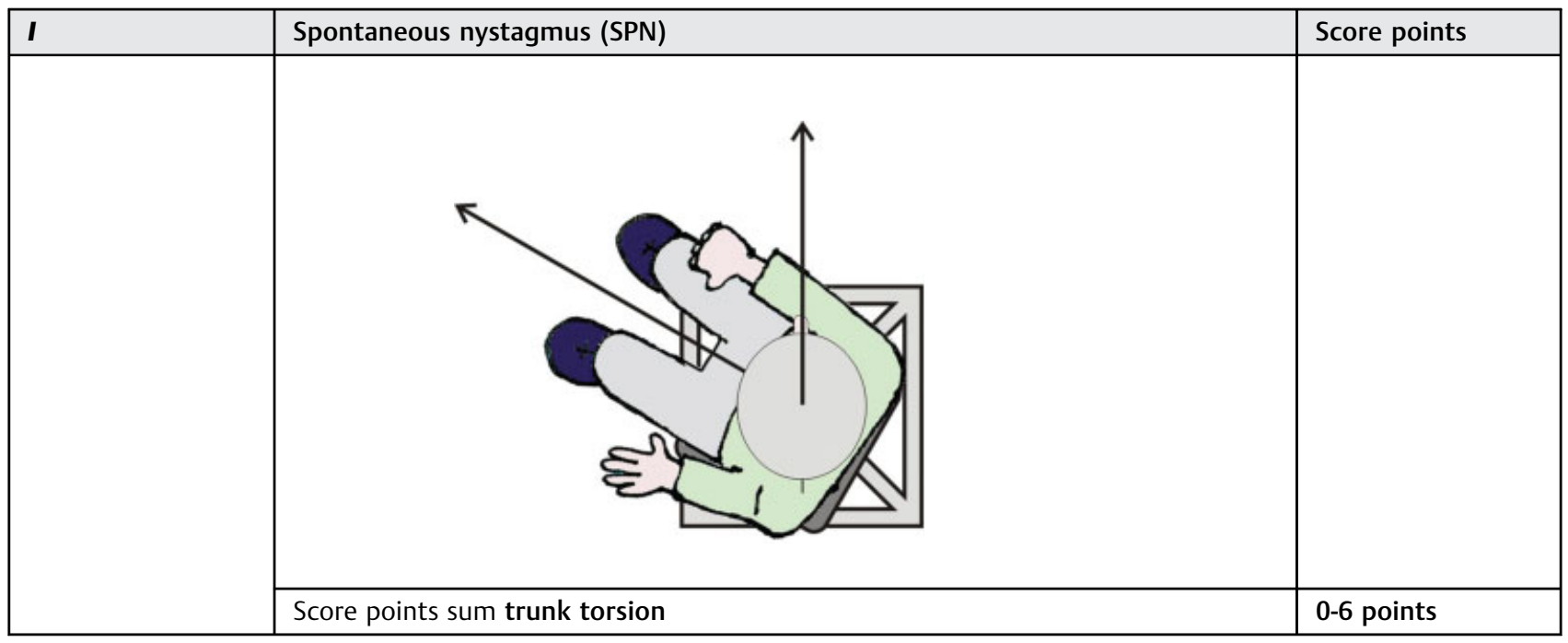

Note: The total score points (0-18) corresponds to the nystagmus amplitude and frequency during a certain trunk position. The static evaluation is shown in - Table 3 .

requirements, and approved by the ethics committee. During the examination on the 3D-trunk-excursion chair, the patient wore a ski helmet supplied by UVEX SPORTS GmbH \& Co. KG, which was electromagnetically connected to the frame of the chair and allowed the head to be fixed in position. The patient could disconnect and stop the experiment with an emergency release button at any time (- Fig. 3). To date, none of the volunteers or patients has used the emergency button. The chair itself is a car seat made of durable fiberglass-enforced plastic (RECARO GmbH \& Co. KG) fixed to a frame, which permits semicircular movements of the chair in space. The chair can pivot freely and allows positioning in three dimensions: lateral tilting to the left and right (trunk tilt) (Table 1), pivoting around its axis to the left and right (trunk torsion) (Table 1) and excursions to the front and back (trunk flexion) (-Table 1 ). A worm drive permits manual positioning of the patient's torso at the desired degree of excursion. Incidental and potentially hazardous back swings of the chair are prevented by a unidirectional worm drive. The degree of excursion is measured by a protractor behind the examination chair. The maximum trunk tilt is $40^{\circ}$, with trunk torsion up to $90^{\circ}$, but only executed to a subjective maximum by the attending physician. The maximum possible trunk flexion is $40^{\circ}$.

\section{Cervicotonic Provocation Nystagmus}

We do not refer to reflex conditions under tonic examination parameters, but to cervicotonic reactions. The corresponding video-oculographic measurement parameter is called the

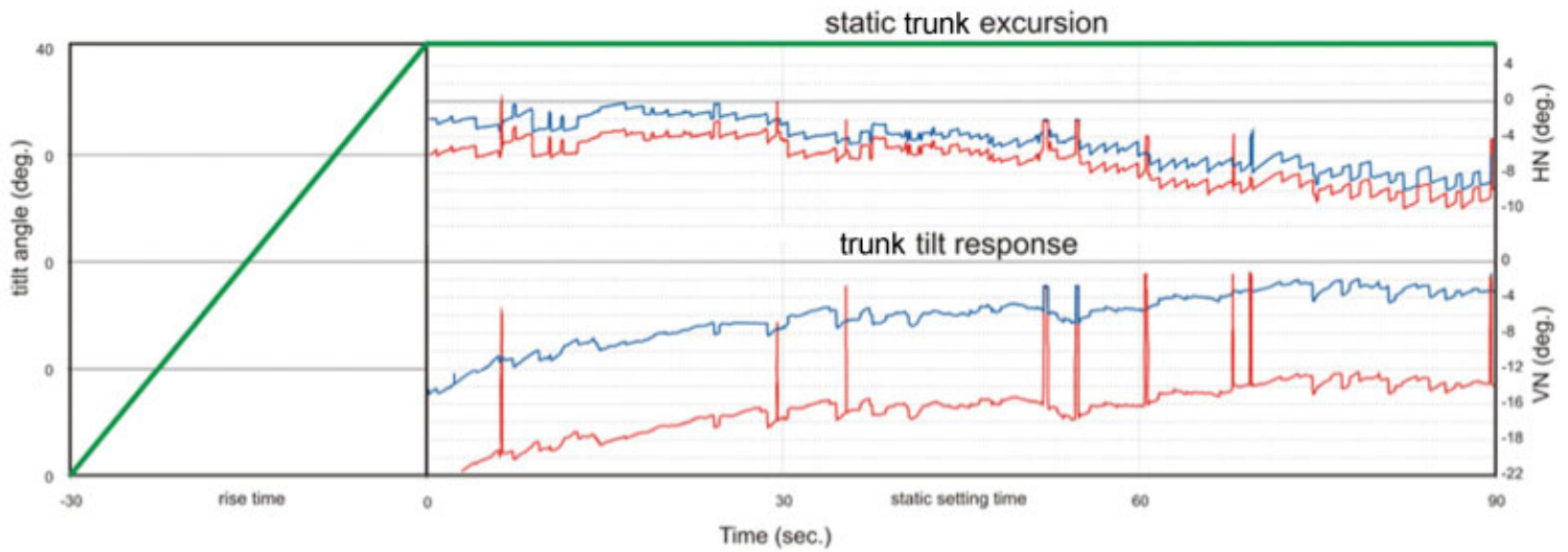

Fig. 4 The figure illustrates the documentation of the nystagmus (horizontal nystagmus and vertical nystagmus) under static trunk excursion on the 3-D-trunk-excursion chair. Before the nystagmus can be recorded, the volunteer has to be positioned in trunk-excursion. The increasing degree of excursion is illustrated with the green bold bar (static trunk excursion). The response (by VN and HN) of the trunk tilt was the beginning of nystagmus recording and measurement at a maximum trunk excursion of $45^{\circ}$ or $90^{\circ}$ under static trunk excursion for a total of 90 seconds. The baseline nystagmus at $0^{\circ}$ is recorded for 90 seconds before the illustrated measurements. Abbreviations: deg., degree; HN, horizontal nystagmus; sec., seconds; VN, vertical nystagmus. 
cervitotonic provocation nystagmus (c-PN). All eye movements were recorded three-dimensionally using with a video system (3D-VOG System, SensoMotoric Instruments (SMI), academic \& medical research at FU Berlin). In particular, the vertical and horizontal nystagmus were measured and documented on the 3D-trunk-excursion-chair under static conditions (- Fig. 4). We prospectively investigated whether placebo-controlled monophasic cervical transcutaneous electrical nerve stimulation (cTENS, SM 1, CE 0197, Pierenkemper GMBH) would influence the c-PN. The study design was based on the assumption that c-TENS application at the upper cervical nerve root levels (C2-C3) would induce a decrease in the action potential frequency of proprioceptive nerve conduction. If we were to show a significant difference between the control and study group, this might be regarded as indicative of the contribution of cervical afferents to head-trunk coordination. Correct c-TENS application at C2-C3 was indicated by selective hypoesthesia of the corresponding occipital dermatomes.

The placebo group's intervention between the two measurements on the 3D-trunk-excursion chair consisted of the placement of a gel pad, placed on the volunteer's upper neck. The gel pad remained on the seated volunteer's neck for 30 minutes, the same resting period between the first and second measurements on the 3D-trunk-excursion chair as in the cTENS group. The gel pad was used in its malleable state, at body temperature, and did not affect the nuchal musculature, cervical proprioception or spinal nerves. The cervicotonic nystagmus reaction was assessed as detailed in section 2.3.1.

This randomized prospective placebo-controlled study included a total of 49 volunteers between 20 and 30 years of age. Both age and gender were matched in the study and control group. Inclusion criteria were a normal otologic, neurologic, micro-, and endoscopic ENT status with an unremarkable Dizziness Handicap Inventory (DHI) score (score $=0)$ and unremarkable CS-status and Halmagyi examination. The study was approved by the Ethics Committee (EA1 / 068 / 09).

\section{Analysis}

As cervical nystagmuses are highly variable and frequent, weak automated assessment only was impossible. In the pilot phase of this study, only visual evaluation criteria were used in the assessment process. Every identification of small nystagmus amplitudes in healthy individuals must be documented precisely. To qualify as a positive nystagmus, at least three consecutive unidirectional nystagmuses had to be detected. We visually graded the velocity and directionality of the slow phase, the directionality of the fast phase, and the frequency of a persisting nystagmus. Three nystagmus categories (I- III) were defined. We categorized "barely" visible nystagmuses as category I (1 point), all clearly visible nystagmuses as category II (2 points), and, finally, all strong nystagmuses with a large amplitude and high frequency were classed as category III (3 points). Non-detectable nystagmuses were scored with 0 score-points. A maximum score of 18 was possible after testing all three trunk positions on the 3D-trunk-excursion chair (-Tables 1 and 2). We compared differences between groups shown in - Fig. 5 using the exact Fisher Test in Chi-Square. We
Table 2 Comparison of the differences between groups for the cervicotonic trunk tilt (applicable also to trunk torsion and flexion)

Comparison of differences for the cervicotonic trunk tilt

\begin{tabular}{|l|l|}
\hline Pre-test trunk tilt & Post-test trunk tilt \\
$0-3$ score points/ & $0-3$ score points/ trunk tilt \\
trunk tilt & Score points sum Post-test \\
$\begin{array}{l}\text { Score points sum } \\
\text { Pre-test trunk tilt } \\
0-6 \text { score points }\end{array}$ & $0-6$ score points \\
\hline
\end{tabular}

evaluated differences between the SPN and the c-PN during trunk flexion using Wilcoxońs test. As the data were nonnormally distributed, the median and interquartile range (IQR) are presented in place of the standard deviation.

\section{Results}

\section{Trunk Excursion Effect in Healthy Individuals}

Prior to the assessment of cervicotonic provocation nystagmus (c-PN) during static trunk excursion, the pre-test spontaneous nystagmus (SPN) was determined (SPN; baseline; neutral position; chair position without cervical strain) in 49 volunteers. The baseline (SPN) measurement showed no significant difference between the placebo and the c-TENS group before and after placebo-controlled cTENS treatment.

After cervicotonic trunk tilting, a trend was noted in the horizontal nystagmus ( $\mathrm{p}=0.077$ ) in comparison to the SPN measurements. A significant increase in vertical nystagmus in cervicotonic trunk ante- and retroflexion (summarized here as "flexion") was demonstrated in young, healthy individuals without vertigo was demonstrated $(\mathrm{p}=0.028)$ (-Fig. 6). The horizontal nystagmus was not significantly altered compared to the SPN during trunk flexion $(\mathrm{p}=0.263)$ (-Fig. 6). No significant differences in nystagmus category were found during trunk torsion compared to the SPN (-Table 3). The interquartile range (IQR) was 0 for the horizontal and vertical SPN and 0.25 for the c-PN during trunk flexion in the horizontal and 0.75 in the vertical dimension.

\section{Effect of Placebo-Controlled c-TENS on Spontaneous Nystagmus}

Possible alterations in the SPN were investigated after placebocontrolled c-TENS (i.e. without cervical provocation). This was achieved using three-dimensional video documentation (3DVOG) and assessment of nystagmuses before and after placebocontrolled c-TENS, compared to the baseline SPN activity (-Table 4). In accordance with the inclusion criteria, most 


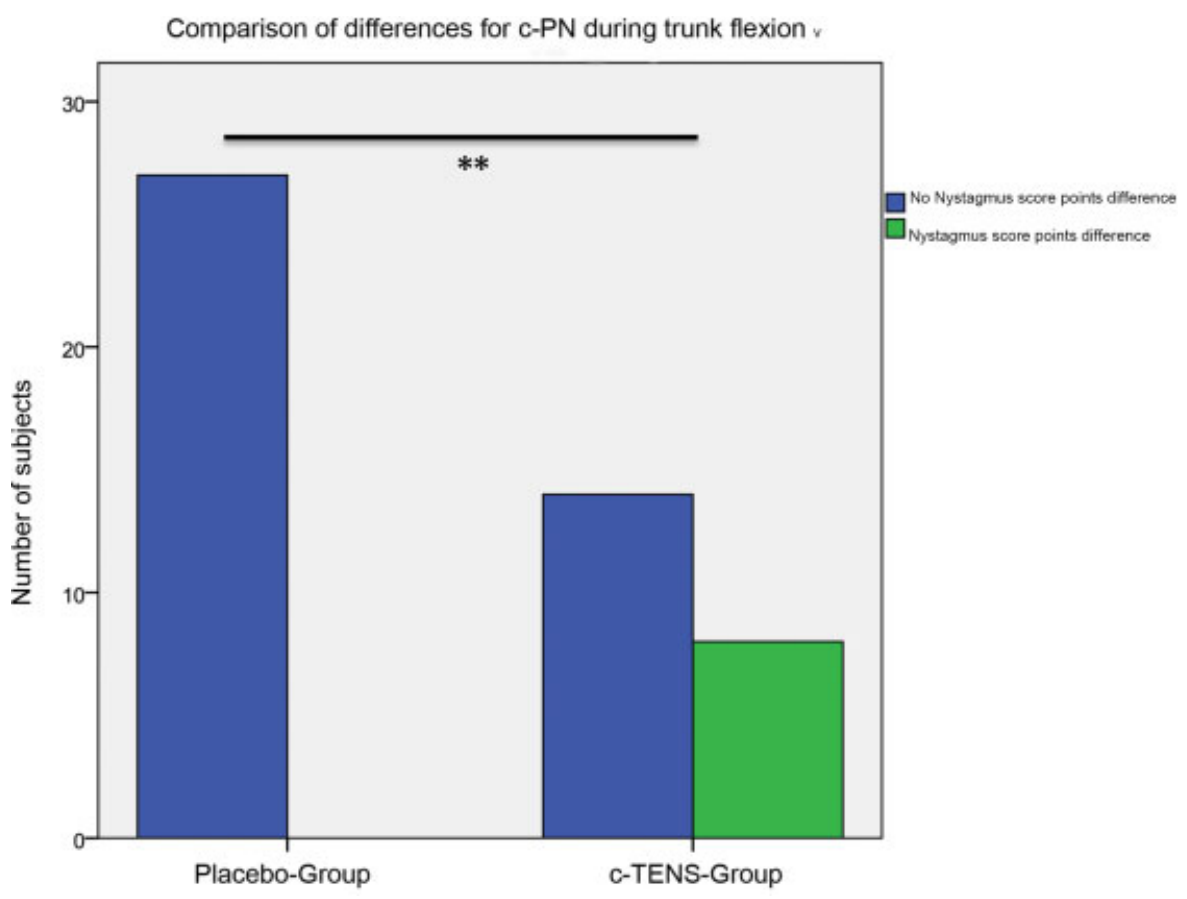

Fig. 5 Comparison of differences for c-PN during trunk flexion ${ }_{v}$. Abbreviations: c-PN, cervicotonic provocation nystagmus; c-TENS, cervical monophasic transcutaneous electrical nerve stimulation.

volunteers had no detectable SPN (nystagmus score points $=0$ ) before placebo-controlled c-TENS application. Individuals in both groups exhibited a slight horizontal SPN $\left(\mathrm{SPN}_{\mathrm{H}}\right)$. The difference in distribution of nystagmus amplitudes and frequency between both groups was not significant $(\mathrm{p}=1.000)$, indicating the statistical comparability of the two groups.

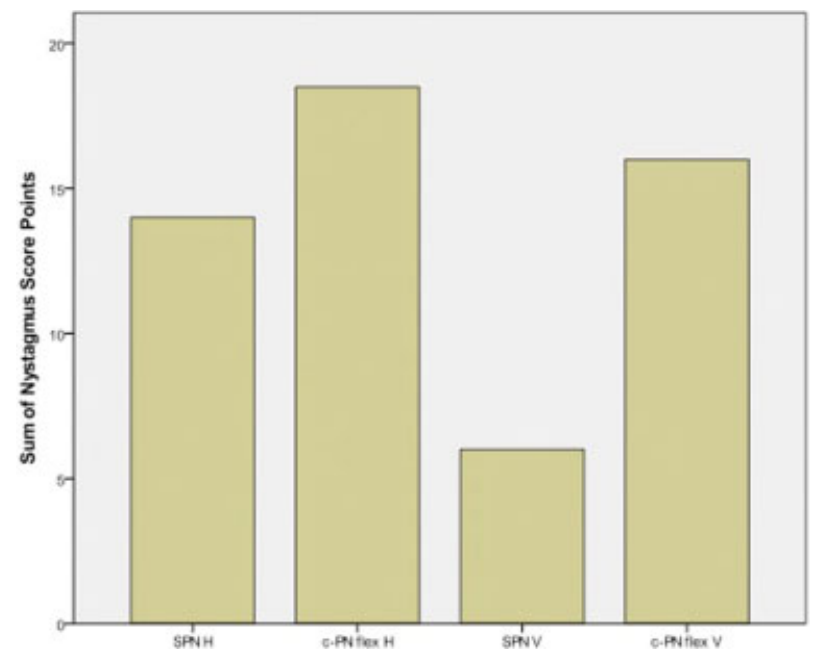

Fig. 6 Wilcoxon Test of the comparisons between nystagmus amplitude and frequency at the baseline (SPN) and the nystagmus occurring during trunk flexion with static head position (trunk flex) for vertical and horizontal nystagmus dimensions. The trunk flexion is a cervical provocation position and induces a c-PN. The p-value for the horizontal nystagmus is 0.549 (n.s.: not significant), the vertical nystagmus is significantly different from the SPN and c-PN with a p-value of $0.026\left(^{*}\right)$. The IQR for the SPN is 0 for the vertical and horizontal dimension and for the c-PN 0.25 for the horizontal and 0.75 for the vertical nystagmus. Abbreviations: c-PN, cervical provocation nystagmus; $\mathrm{H}$, horizontal; SPN, spontaneous nystagmus; $\mathrm{V}$, vertical.
After c-TENS application (post-test SPN), the subsequent measurement in neutral trunk position did not differ significantly between the c-TENS and the control group (placebo), ( $p>0.05$ ). Likewise, the horizontal and vertical nystagmuses in the c-TENS group did not differ significantly from those detected in the placebo group $(\mathrm{p}=0.395$ and $\mathrm{p}=0.536$, respectively).

\section{Effect of Placebo-Controlled c-TENS on Cervicotonic Provocation Nystagmus}

The third part of the analysis focused on the question whether cervical provocation with various tonic trunk excursions on the 3D-trunk-excursion chair can be modulated by c-TENS in a placebo-controlled set-up. The result was a significant difference between the two groups for trunk flexion and the vertical nystagmus $(\mathrm{p}=0.001, \mathrm{p}=0.005$, and $\mathrm{p}=0.001$ for trunk flexion, torsion, and tilt) (-Fig. 5); that is, significantly less provocation nystagmuses in the c-TENS group.

Table 3 Summary table including the results of neck tilt, flexion, and torsion and the corresponding observed nystagmus in each provocation position and spontaneous nystagmus of the 49 normal subjects on the 3D-trunk-excursion chair

\begin{tabular}{l} 
Exemplary calculation for the cervicotonic trunk tilt \\
\hline Post-test - Pre-test $=$ comparison of differences \\
Score points: \\
Pre-test: 3 (tilt to the right) +3 (tilt to the left) $=6$ \\
Post-test: 1 (tilt to the right) +1 (tilt to the left) $=2$ \\
Comparison of differences: \\
Post-test - Pre-test $=2-6=-4$
\end{tabular}




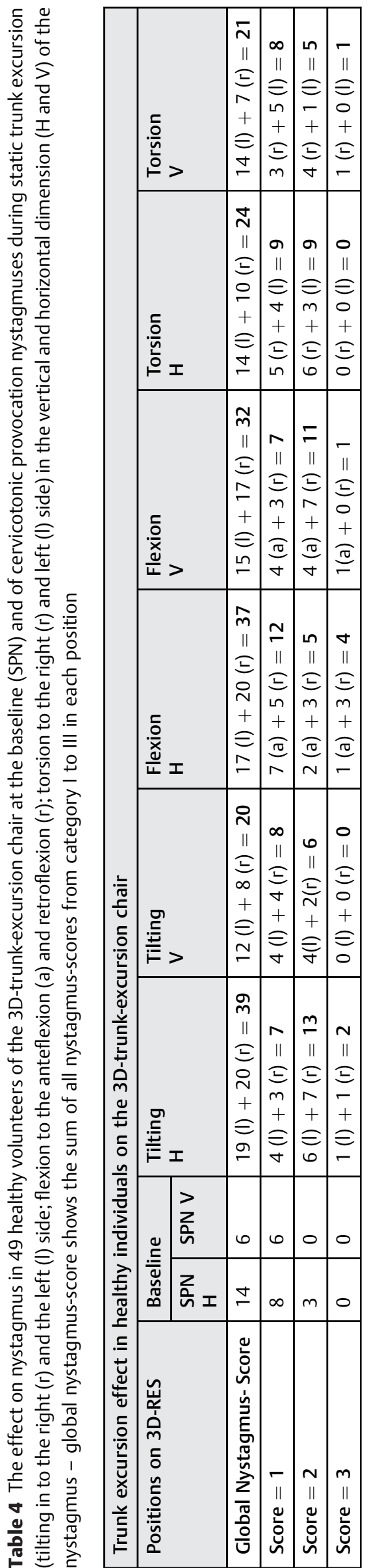

The horizontal nystagmus decreased significantly after cTENS during trunk flexion and tilting $(\mathrm{p}=0.024$, and $\mathrm{p}=0.035$ ).

In summary, the initial increase in c-PN in static trunk flexion was reduced after applying c-TENS. This effect was confirmed by a further reduction in c-PN in the trunk tilt position in the c-TENS group. Trunk torsion had a significant effect on the vertical nystagmus and no significant effect on the horizontal nystagumus $(\mathrm{p}=0.368)$. Nystagmus intensity was reduced significantly in the $\mathrm{c}-\mathrm{TENS}$ group $(\mathrm{p}=0.005)$.

\section{Discussion}

The cervico-ocular reflex (COR) plays a much-disputed role in the highly complex concert of intra- and extracranial vestibular reflexes. ${ }^{18-20}$ In the literature, the acronym COR is used to describe two very common but also quite different concepts. To some authors, COR means cervico-ocular reaction, ${ }^{21}$ whereas to others it means cervico-ocular reflex. ${ }^{22}$

The somato-sensory afferents relevant to the vestibular computation originate in the upper cervical spine. Suboccipital muscles are some of the richest in terms of muscle spindles. ${ }^{23}$ Both neuroanatomical and electrophysiological examinations show direct proprioceptive afferents from the upper cervical segments to the vestibular nucleic complex. ${ }^{7,8,11}$ However, spino-vestibular afferents from more distal spinal segments however are sparse. Ia-afferents (dynamic function) and II-afferents (static function) originate from the muscle spindles' nuclear bag and nuclear chain fibers. Predominantly la-afferent fibers project to the central cervical nucleus and on to the vestibular nuclei. ${ }^{9,10}$ However, it remains unclear whether primary cervical afferents to the cervical nucleus are also mostly la-fibers (- Fig. 7).

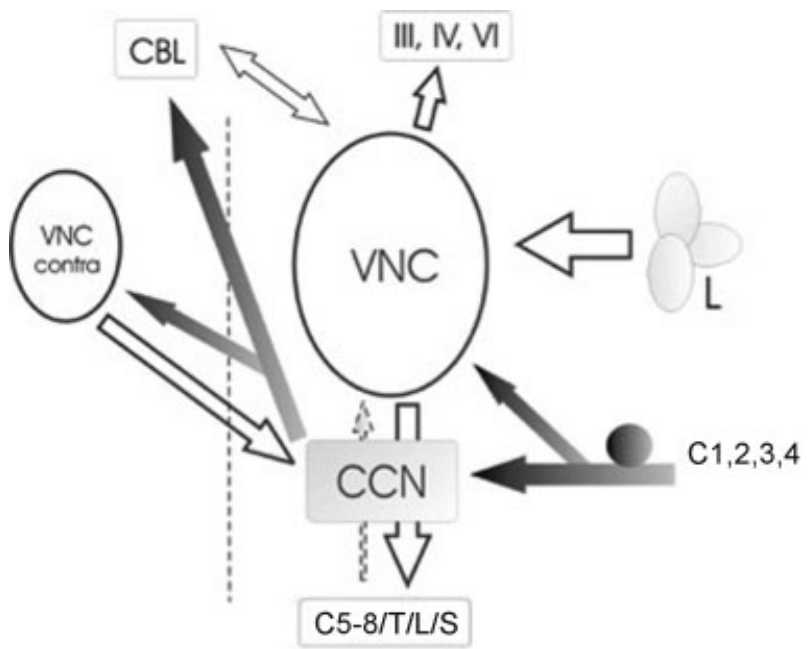

Fig. 7 Schematic of proprioceptive afferents (grey) from the upper cervical spine ( $C 1-4)$ in context with the VNC, and its most important connections. Note the direct projections from ipsilateral VNC, while afferents from the $\mathrm{CCN}$ reach the contralateral VCN. Afferents to the VCN from lower cervical, thoracic, lumbar, and sacral spinal segments are sparse (dotted arrow). Abbreviations: III,IV,VI, oculomotor, trochlear, and abducens nerve; $\mathrm{CBL}$ : cerebellum; $\mathrm{CCN}$ : central cervical nucleus; L: labyrinth; VNC, vestibular nucleic complex 
Regardless of the confusion over definition, Rijkaart et al highlight the clinical validity of the COR. Under phasic conditions, the authors were able to demonstrate the interaction between COR and the vestibulo-ocular reflex (VOR), the optokinetic reflex (OKN) and smooth pursuit. Their study was based on the notion that, for the most part, reflex mechanisms control visual field stabilization during head movements. $^{24}$

Other authors support the hypothesis of a reflex mechanism and attribute the COR, VOR and OKN to synergistic reflex function. ${ }^{25}$ As opposed to the VOR, the COR's and the OKN's reflex mechanisms coordinate slower head movements. Kelders et al were able to demonstrate an age-dependent difference in "gain", ${ }^{26}$ whilst Mandellos et al found an increase in "gain" in patients with labyrinthine dysfunction. ${ }^{18}$ According to Kelders et al and Montoort et al, patients who had suffered whiplash injuries showed a significant increase in "gain" compared to healthy volunteers. ${ }^{25,27}$

Studies in healthy adults have shown a non-linear increase in signal flow from the cervical region. During a purely cervical proprioceptive trunk movement under a fixated head, the "gain" corresponds to the perception, measured by the actual relative deflection between head and trunk with a medium value of $0.3-1.0 \mathrm{~Hz}$ and with an angular velocity of $20^{\circ} \mathrm{s}$, or an angular acceleration of $50^{\circ} / \mathrm{s}^{2}$ (everyday movements, slow rotations). ${ }^{28}$

Treleaven et al have noted the special role of the craniocervical junction in slower eye movements (smooth pursuit). According to Treleaven it is possible to identify patients with impaired cervical proprioception, known as whiplash patients, using the so-called "smooth pursuit neck torsion test". ${ }^{29,30}$ This method has been validated in many of Treleaven et al's and other authors' studies, and has evolved to become an important method in cervical proprioceptive diagnostics. $^{30-32}$

With a complex and elaborate investigation set-up and many inter-individual variables, the COR assessment is prone to a multitude of external variables and errors. From a diagnostic point of view, it would be beneficial to develop and establish an easy and reproducible test that is feasible in the clinical setting.

\section{Diagnostic Aspects}

The so-called "neck torsion test" (NTT) is described in the literature as a practical examination method. Cervical induced horizontal nystagmuses, which is mainly provoked by trunk rotation, has been discussed here at length. ${ }^{12,33-35}$ The advantage of this method is that the cervical nystagmus is recorded using video-oculography and can be used as an objective measurement parameter. A problematic aspect is, however, that very little is known to date about cervical nystagmus, as very little systematic scientific research exists on the topic. Results from individual tonic and phasic studies in healthy volunteers and cervically impaired patients have been buried in unfortunate discussions over dogmatic paradigms. ${ }^{12,36}$

Nevertheless, some preliminary data have pointed out the role of the vertical nystagmus during the examination in trunk excursion ${ }^{16}$. Aside from the role of the horizontal nystagmus, the importance of the vertical nystagmus for positions involving trunk flexion has also been asserted. In almost all of the studied cases the vertical nystagmus was an up-beat nystagmus. Some of our own preliminary research on the 3D-neck torsion test discusses the significance of the up-beat nystagmus during trunk excursion 13,16,37. In another study, this knowledge was used in young, healthy volunteers, who were then compared to a group of patients with vestibular, or cervical impairment. Again, the vertical nystagmus proved to be a decisive factor in differentiating different patient groups from healthy volunteers. Under these circumstances, we presumed that a cervical straining position on the 3D-trunk excursion chair would also provoke a c-PN in healthy individuals. This hypothesis was verified by our results, which showed a c-PN in healthy volunteers. As we were able to demonstrate in our previous study, a significant increase in vertical nystagmus compared to SPN was observed during tonic static trunk excursion. This cervical proprioceptive activation of the vestibular system can be measured using the c-PN and may be significantly weakened by c-TENS.

In agreement with many other authors, Castro et al found that vestibular symptoms after cervical soft tissue acceleration could be attributed to psychogenic causes in their socalled "zero study". ${ }^{38}$ We do not dispute the validity of this study, as it illustrates the complex influences on the vestibular system. However, as long as cervical receptor function cannot be examined to a diagnostically satisfactory level, the sole psychopathological etiology of vestibular symptoms should be viewed critically. It is the authors' belief that as physicians we should continue to investigate and research cervico-vestibular examination methods to better differentiate organic pathology from psychogenic vestibular symptoms. This is where we hope our study will contribute to further research and diagnostic advances.

\section{Therapeutic Aspects}

In 1988, Bogduk was able to elucidate some general aspects of functional and painful cervical spine disorders. ${ }^{39}$ With a specifically induced pain reaction (infiltration with hypertonic sodium solution or an anesthetic into the dorsal branches of the spinal nerves or the intervertebral joints, respectively) and subsequent radiation of pain to specific segments, Bogduk was able to illustrate the pathomechanism of cervical pain and its radiation along sensory fibers.

Based on these findings, Dreyfuss investigated the transmission of pain after injections into the $\mathrm{CO} / \mathrm{C} 1$ and $\mathrm{C} 1 / \mathrm{C} 2$ intervertebral joints - the volunteers reported an occipital sensation of pain after atloido-occipital joint injections, and retro auricular pain after atlantoido-axial joint infiltrations. ${ }^{40}$ These findings gave rise to the development of cervical radiofrequency-neurotomy (CRFN). Today, this method is a routine procedure in the treatment of cervical pain. The procedure relies on thermal destruction of the pain-transmitting nerve fibers. A puncture needle is advanced to the target nerve under CT-guidance. The nerve is then treated with radiofrequency ablation at temperatures up to $80-90^{\circ} \mathrm{C}$ for 60-90 seconds. Also based on Bogduk's studies, Prushansky et al were able to illustrate a positive placebo-controlled 
effect of cervical CRFN in patients with symptoms after a whiplash injury in a randomized double-blinded study. ${ }^{41}$ Several groups have since confirmed these findings, and have successfully treated pain syndromes after whiplash injuries with CRFN. ${ }^{42,43}$

\section{Conclusion}

Our results indicate that there is a "cervicotonic provocation nystagmus" in response to objective reaction to cervical straining with a static trunk excursion. We consider this to be indicative of a contribution of cervical afferents to vestibular head-trunk-coordination. The detailed results obtained on the 3D-trunk-excursion chair, in combination with cervical TENS may contribute to new therapeutic modules.

To summarize our results thus far for the Three-dimensional trunk-excursion chair:

1. A cervicotonic provocation nystagmus (c-PN) can be detected in individuals with a healthy vestibular system.

2. No change in spontaneous nystagmus at the baseline was observed with videonystagmography after placebo-controlled c-TENS.

3. c-PN can be suppressed using placebo-controlled c-TENS. This effect is most significant for the vertical nystagmus.

\section{References}

1 Hanes DA. Perceptual centering of body segment orientation. J Vestib Res 2007;17(5-6):251-270

2 Chan YS, Lai CH, Shum DK. Bilateral otolith contribution to spatial coding in the vestibular system. J Biomed Sci 2002;9(6 Pt 2):574-586

3 Green AM, Angelaki DE. Coordinate transformations and sensory integration in the detection of spatial orientation and selfmotion: from models to experiments. Prog Brain Res 2007; 165:155-180

4 Green AM, Shaikh AG, Angelaki DE. Sensory vestibular contributions to constructing internal models of self-motion. J Neural Eng 2005;2(3):S164-S179

5 Scherer H, Clarke AH, Baetke F. [Physiology of the caloric equilibrium reaction. Consequences from results of space experiments in Spacelab 1, December 1983]. Laryngol Rhinol Otol (Stuttg) 1985; 64(5):263-268

6 Parker DE. Spatial perception changes associated with space flight: implications for adaptation to altered inertial environments. J Vestib Res 2003;13(4-6):331-343

7 Neuhuber WL, Zenker W. Central distribution of cervical primary afferents in the rat, with emphasis on proprioceptive projections to vestibular, perihypoglossal, and upper thoracic spinal nuclei. J Comp Neurol 1989;280(2):231-253

8 Matsushita M, Gao X, Yaginuma H. Spinovestibular projections in the rat, with particular reference to projections from the central cervical nucleus to the lateral vestibular nucleus. J Comp Neurol 1995;361(2):334-4

9 Keirstead SA, Rose PK. Structure of the intraspinal projections of single, identified muscle spindle afferents from neck muscles of the cat. J Neurosci 1988;8(9):3413-3426

10 Thomson DB, Isu N, Wilson VJ. Responses of neurons of the cat central cervical nucleus to natural neck and vestibular stimulation. J Neurophysiol 1996;76(4):2786-2789

11 Kasper J, Schor RH, Wilson VJ. Response of vestibular neurons to head rotations in vertical planes. I. Response to vestibular stimulation. J Neurophysiol 1988;60(5):1753-1764
12 Holtmann S, Reiman V, Scherer H. Cervico-ocular eye movements in relation to different neck torsion velocities. Acta Otolaryngol Suppl 1989;468:191-196

13 Hölzl M, Gabel P, Weikert S, Orawa H, Scherer H. [Influence of different head-trunk positions to the upbeat-nystagmus]. Laryngorhinootologie 2009;88(2):92-100

14 Ceyte H, Trousselard M, Barraud PA, Roux A, Cian C. Perceived head-trunk angle during microgravity produced by parabolic flight. Aviat Space Environ Med 2008;79(4):420-423

15 Bove M, Courtine G, Schieppati M. Neck muscle vibration and spatial orientation during stepping in place in humans. J Neurophysiol 2002;88(5):2232-2241

16 Hölzl M, Weikert S, Gabel P, Topp N, Orawa H, Scherer H. [Cervicoproprioceptive provocation of horizontal and vertical nystagmus in test subjects]. HNO 2008;56(10):1013-1019

17 Ladenbauer J, Minassian K, Hofstoetter US, Dimitrijevic MR, Rattay F. Stimulation of the human lumbar spinal cord with implanted and surface electrodes: a computer simulation study. IEEE Trans Neural Syst Rehabil Eng 2010;18(6):637-645

18 Mandellos D, Anastasopoulos D, Becker W. Smooth pursuit rather than visual signals mediate short-term adaptation of the cervico-ocular reflex in humans. Exp Brain Res 2006;169(2): 153-161

19 Pettorossi VE, Manni E, Errico P, Ferraresi A, Bortolami R. Otolithic and extraocular muscle proprioceptive influences on the spatial organization of the vestibulo- and cervico-ocular quick phases. Acta Otolaryngol 1997;117(2):139-142

20 Bronstein AM, Morland AB, Ruddock KH, Gresty MA. Recovery from bilateral vestibular failure: implications for visual and cervicoocular function. Acta Otolaryngol Suppl 1995;520(Pt 2):405-407

21 Doerr M, Thoden U. Eye movements during voluntary head motion with minimized cervical input. Arch Otorhinolaryngol 1989; 246(1):20-25

22 Montfoort I, Van Der Geest JN, Slijper HP, De Zeeuw CI, Frens MA. Adaptation of the cervico- and vestibulo-ocular reflex in whiplash injury patients. J Neurotrauma 2008;25(6):687-693

23 Banks RW. An allometric analysis of the number of muscle spindles in mammalian skeletal muscles. J Anat 2006;208(6):753-768

24 Rijkaart DC, van der Geest JN, Kelders WP, de Zeeuw CI, Frens MA. Short-term adaptation of the cervico-ocular reflex. Exp Brain Res 2004;156(1):124-128

25 Kelders WP, Kleinrensink GJ, van der Geest JN, et al. The cervicoocular reflex is increased in whiplash injury patients. J Neurotrauma 2005;22(1):133-137

26 Kelders WP, Kleinrensink GJ, van der Geest JN, Feenstra L, de Zeeuw $\mathrm{CI}$, Frens MA. Compensatory increase of the cervico-ocular reflex with age in healthy humans. J Physiol 2003;553(Pt 1):311-317

27 Montfoort I, Kelders WP, van der Geest JN, et al. Interaction between ocular stabilization reflexes in patients with whiplash injury. Invest Ophthalmol Vis Sci 2006;47(7):2881-2884

28 Mergner T, Siebold C, Schweigart G, Becker W. Human perception of horizontal trunk and head rotation in space during vestibular and neck stimulation. Exp Brain Res 1991;85(2):389-404

29 Tjell C, Rosenhall U. Smooth pursuit neck torsion test: a specific test for cervical dizziness. Am J Otol 1998;19(1):76-81

30 Treleaven J, Jull G, LowChoy N. Smooth pursuit neck torsion test in whiplash-associated disorders: relationship to self-reports of neck pain and disability, dizziness and anxiety. J Rehabil Med 2005; 37(4):219-223

31 Marti S, Bockisch CJ, Straumann D. Prolonged asymmetric smooth-pursuit stimulation leads to downbeat nystagmus in healthy human subjects. Invest Ophthalmol Vis Sci 2005;46(1): 143-149

32 Treleaven J, Jull G, LowChoy N. The relationship of cervical joint position error to balance and eye movement disturbances in persistent whiplash. Man Ther 2006;11(2):99-106

33 Hülse M, Seifert K. [Cervicogenic head and neck pain]. HNO 2005; 53(9):804-809 
34 Scherer H. [Neck-induced vertigo]. Arch Otorhinolaryngol Suppl $1985 ; 2: 107-124$

35 Norré ME. Cervical vertigo. Diagnostic and semiological problem with special emphasis upon "cervical nystagmus". Acta Otorhinolaryngol Belg 1987;41(3):436-452

36 Holtmann S, Reiman V, Schöps P. [Clinical significance of cervicoocular reactions]. Laryngorhinootologie 1993;72(6):306-310

37 Weikert S, Gabel P, Orawa H, Scholz P, Scherer H, Hölzl M. [Investigations concerning the head-trunk-coordination]. Laryngorhinootologie 2008;87(4):245-251

38 Castro WH, Meyer SJ, Becke ME, et al. No stress-no whiplash? Prevalence of "whiplash" symptoms following exposure to a placebo rear-end collision. Int J Legal Med 2001;114(6):316-322
39 Bogduk N, Marsland A. The cervical zygapophysial joints as a source of neck pain. Spine 1988;13(6):610-617

40 Dreyfuss P, Michaelsen M, Fletcher D. Atlanto-occipital and lateral atlanto-axial joint pain patterns. Spine 1994;19(10): 1125-1131

41 Prushansky T, Pevzner E, Gordon C, Dvir Z. Cervical radiofrequency neurotomy in patients with chronic whiplash: a study of multiple outcome measures. J Neurosurg Spine 2006;4(5):365-373

42 Lord SM, Barnsley L, Bogduk N. Percutaneous radiofrequency neurotomy in the treatment of cervical zygapophysial joint pain: a caution. Neurosurgery 1995;36(4):732-739

43 Sapir DA. Cutaneous application of ethyl chloride spray. Reg Anesth 1995;20(3):260 